is a well-made boy, twelve years of age, fair hair, and blue eyes. When I first saw him he was suffering from acute rheumatism of both shoulder-joints, which were very much swollen, and intensely painful on pressure; pulse quick; tongue furred; perspiration acid in smell. He was ordered a brisk purgative, and then put under the bicarbonate of potash, ten grains every three or four hours, and Dover's powder, four grains every night if necessary. He made a good recovery under this treatment; in fact, in about a month he was pretty well again. At the beginning of September I was requested to see him again. I found him suffering from chorea: the left side of the face and upper limbs were affected most; the legs were steady, as he could walk across the room without much effort. His mother informed me that the urine frequently had a lateritious sediment in it. The bowels are variable, but not constipated as a rule; the appetite ravenous. There has never been any heart complication throughout. He is progressing well under strychnine and iron and a plain nourishing diet. The family history does not point to the rheumatic diathesis.

Doncaster, Oct. 1868.

\section{A CASE OF SPONTANEOUS EVOLUTION.}

Br P. MACDONALD BELL, M.B., C.M.

IN the spring of $1867 \mathrm{I}$ was called to attend a confinement in the village of Blairlogie, Stirlingshire. The case was in charge of a midwife, who, six hours before my arrival, had delivered the woman of one child of twins, the second remaining in utero. On examination, I found the outlet of the pelvis occupied by a large, soft, round body, which so completely filled the space as to render examination a matter of great difficulty. At first I thought the child's head was presenting, and that the softness of the mass might be accounted for by a hydrocephalic condition. At the same time I was not at all satisfied with my diagnosis, inasmuch as I could not detect a face, nor could I trace anything corresponding to a normal neck or shoulder. I got, however, a sulcus between two ribs (as I found afterwards), which I was induced to regard as the sagittal suture. I certainly could come to no satisfactory conclusion. Birth shortly afterwards took place without any alteration in the child's position, the pains being strong and forcing. The presenting part was in the right hypochondriac region, which was bulged out into a complete hemisphere. The child was quite doubled up, its head resting upon its heels, and a second globular swelling formed upon its throat. It was perfectly formed, of a good size for a twin, and, according to the mother's reckoning, was at full time. It was dead of course. The first child was somewhat tedious in the birth, but came away naturally. The mother (a multipara) was a stout, healthy young woman, short of stature, pelvis and passages roomy. She made a good recovery.

Pudsey, Leeds, Sept. 1868.

\section{a siltirtor}

OF THE PRACTICE OF

\section{MEDICINE AND SURGERY IN THE}

HOSPITALS OF LONDON.

Nulla autem est alia pro certo noscendi via, nisi quamplurimas et morborum el dissectionum historias, tum aliorum, tum proprias collectas habere, et inter se comparare.-Mongagni De Sed. et Caus. Morb., lib. iv. Procmium.

\section{ST. THOMAS'S HOSPITAL.}

COMPOUND FRACTURE OF THE SKULL, WITH DEPRESSION ; ERYSIPEIAS ; RECOVERY.

(Under the care of Mr. Sydney Jones.)

THE following is an interesting case of recovery from very severe injury. The notes of the temperature are particularly worthy of observation.

Edward W-_ aged twenty-nine, railway porter, of reputed temperate habits, was admitted October 2nd, 1867. Whilst endeavouring to avoid an approaching train he had been knocked down by an engine passing in an opposite direction. He was admitted about an hour after the accident, and was stated to have suffered from concussion, and to have lost a good deal of blood, some of which he had vomited. Upon examina. tion there was found above the left frontal eminence a crescentshaped wound, about two inches and a half in transverse measurement, at the bottom of which a fracture could be readily detected, passing at first transversely inwards, and then descending vertically, an angular portion of the frontal, below the left eminence, being depressed for about a couple of lines below the general level of the bone. There was also laceration of the left ear, from which there was much hæmorrhage; but there was no bleeding from the meatus. There was also contusion over the left malar bone, and both upper eyelids were much swollen. There was, however, no sub-conjunciival ecchymosis.

When admitted at 11 A.M. he was quite conscious. He complained of headache; the pupils were equal and contracted normally; pulse 120 . The head was shaver, and an ice-bag applied. One hour afterwards he vomited about two ounces of blood. Some calomel and compound senna mixture, after being retained for a short period, were ejected, mixed with a small quantity of blood. Later in the day beef-tea and ice were retained. Was able to pass urine freely; no paralysis. Soup diet.

Oct. 3rd.-Has slept a little during the night, but complains of severe pain in the head. The eyelids are much swollen and quite closed. There having been no relief of the bowels, two ounces of compound senna mixture were ordered, and produced one free evacuation at four P.M., and a second, less copious, at ten P.M.

4th. - Slept better during the night. Tongue moist and tolerably clean ; pulse 108; eyelids less swollen, but much discoloured. Was able to eat some rice pudding for his dinner, and seemed to enjoy it.

5th.-Has great pain and tenderness behind the left ear; the ear also is much swollen. Has less pain in the head. Temperature $996^{\circ}$; pulse 110 ; tongue furred. Compound senna mixture, two ounces.

6 th. -Pain behind the ear less, but redness more extended. Bowels not relieved. Temperature $1034^{\circ}$; pulse 108 . Blue pill and colocynth.

8th. - Redness behind the ear not increased. Has vomited, and had inclination to retch. Bowels sluggish. Temperature $105^{\circ}$; pulse 116 . Two ounces of senna mixture.

9th.- Has had a bad night, in consequence of pain on the right side of the neck; this is red, swollen, and very tender. Bowels well relieved last night and again this morning. Tem. perature $103 \cdot 8^{\circ}$; pulse 120 . Solution of acetate of ammonia, two drachms every four hours. Beef-tea and nourishing unstimulating diet ordered.

11th.-Erysipelas of head and neck; the latter much swollen. There is considerable discharge from the wounds of the forehead and ear. He complains of but little pain. Towards night he is delirious. Temperature $1016^{\circ}$; pulse 120 . Ordered an enema.

12th. -Was very delirious and raving during the night, but is much calmer this morning. In the night twenty minims of solution of morphia were subcutaneously injected, and with great benefit. Temperature $100^{\circ}$; pulse 112 .

14th. - Better. Temperature $99^{\circ}$; pulse 112

15th.-Wound of forehead discharging freely. A small collection of pus being discovered over the left malar bone, Mr. Sydney Jones evacuated it. Ice-bag still continued to head; fomentations to neck. Face and neck much less swollen. Appetite better. Temperature $99 \cdot 4^{\circ}$; pulse 100 . Bowels not relieved since the 11th. Ordered colccynth and calomel, ten grains.

19th.--Mr. Sydney Jones incised the scalp in the occipital region, and evacuated about two drachms of pus. Discontinue ice-bag. Repeat pill.

21st.-Has now no delirium; frontal wound discharging freely; erysipelas nearly gone; appetite improving.

22 nd. - Wound towards occiput discharges a little; that of frontal is healing over. Fish, eggs.

25th. -Takes his food well; sleeps well; the wounds look healthy. Slice.

30th. - Wound of forehead gradually diminishing, but bare bone to be felt at bottom.

Nov. 6th.-Allowed to sit up during a portion of the day.

From this time he gradually progressed. On the 4th of December a thin shell of bone was removed from the frontal wound, which then soon closed, and he was discharged well on the 7 th of December. 